\title{
Tolerability in the elderly population of high-dose alpha lipoic acid: a potential antioxidant therapy for the eye
}

This article was published in the following Dove Press journal:

Clinical Ophthalmology

29 September 2016

Number of times this article has been viewed

\section{Daniel Sarezky \\ Aaishah R Raquib \\ Joshua L Dunaief \\ Benjamin J Kim}

Scheie Eye Institute, Department of Ophthalmology, Perelman School of Medicine, University of Pennsylvania, Philadelphia, PA, USA
Correspondence: Benjamin J Kim Scheie Eye Institute, Department of Ophthalmology, Perelman School of Medicine, University of Pennsylvania, 5I N 39th St, Philadelphia, PA 19104, USA

Tel +l 2I5 6628675

Fax +I 2152434696

Email benjamin.kim@uphs.upenn.edu
Purpose: Alpha lipoic acid (ALA) is an antioxidant and iron-chelating supplement that has potential benefits for geographic atrophy in dry age-related macular degeneration as well as other eye diseases. The purpose of this study was to determine the tolerability of ALA in the elderly population.

Patients and methods: Fifteen subjects, age $\geq 65$ years, took sequential ALA doses of 600 , 800 , and 1,200 mg. Each dose was taken once daily with a meal for 5 days. After each dose was taken by the subjects for 5 days, the subjects were contacted by phone, a review of systems was performed, and they were asked if they thought they could tolerate taking that dose of ALA for an extended period of time.

Results: The $600 \mathrm{mg}$ dose was well tolerated. At the $800 \mathrm{mg}$ dose, one subject had an intolerable flushing sensation. At the 1,200 mg dose, two subjects had intolerable upper gastrointestinal side effects and one subject had an intolerable flushing sensation. Subjects taking gastrointestinal prophylaxis medications had no upper gastrointestinal side effects.

Conclusion: High-dose ALA is not completely tolerated by the elderly. These preliminary data suggest that gastrointestinal prophylaxis may improve tolerability. (ClinicalTrials.gov, NCT02613572).

Keywords: age-related macular degeneration, geographic atrophy, antioxidant, gastrointestinal, dietary supplements, lipoic acid

\section{Introduction}

Alpha lipoic acid (ALA) is an over-the-counter supplement that can function as a potent antioxidant and iron chelator. The functions of ALA also include restoration of diminished levels of other antioxidants, anti-inflammatory effects, and increased insulin sensitivity. ${ }^{1,2}$ While the Age-Related Eye Disease Study (AREDS) antioxidant vitamins are not known to affect glutathione, an important natural antioxidant, ALA increases intracellular glutathione levels..$^{3-7}$ ALA is already in use for the treatment of diabetic peripheral neuropathy, ${ }^{8}$ and may have benefits in other disease processes, including multiple sclerosis ${ }^{9-11}$ and Alzheimer's disease. ${ }^{12}$ Importantly, ALA was also found to have benefits in animal models of a number of ocular diseases, including diabetic retinopathy, ${ }^{13,14}$ glaucoma, ${ }^{15}$ dry eye, ${ }^{16}$ and optic neuritis. ${ }^{17}$

The geographic atrophy of the retina that develops in advanced nonexudative (dry) age-related macular degeneration (AMD) is responsible for $20 \%$ of the legal blindness in the US, and there is no treatment for it. ${ }^{18}$ The pathophysiology of AMD is thought to involve multiple mechanisms including inflammation and oxidative stress, in part through photo-oxidative retinal damage and iron overload. ${ }^{19}$ High-dose 
antioxidant vitamins and minerals have already been shown by the AREDS to decrease progression of the intermediate stage of dry AMD, ${ }^{6,7}$ but the AREDS vitamins are not known to greatly affect geographic atrophy growth rates. ${ }^{20}$ Using a mouse model of light-induced retinal degeneration, Zhao et al demonstrated that systemic treatment with ALA had a significant protective effect on the retina. ${ }^{21}$ Based on these findings, the authors suggested evaluating ALA in a clinical trial for AMD.

Over-the-counter doses of ALA typically range from 100 to $600 \mathrm{mg}$ daily. Following ingestion, peak serum levels of ALA are found after 50-90 minutes, and it is undetectable by about 5 hours. ${ }^{10}$ Yadav et al found that a high dose (1,200 mg) of ALA taken once daily leads to peak serum levels that are potentially therapeutic and significantly higher than those resulting from a $600 \mathrm{mg}$ dose. ${ }^{9}$ While gastrointestinal (GI) side effects from ALA have been reported, ${ }^{8,9}$ the same authors described 24 subjects with a median age of 51 who all tolerated a dose of 1,200 $\mathrm{mg}$ of racemic ALA taken with a standardized meal. ${ }^{10}$ This study suggested that taking a high dose of ALA with a meal ameliorates the GI side effects, but still achieves potentially therapeutic serum levels. Currently, $1,200 \mathrm{mg}$ is the study dose in an ongoing clinical trial for optic neuritis (ClinicalTrials.gov, NCT01294176). Given the lack of high-dose ALA tolerability data specifically for the elderly population, a Phase I clinical trial was completed evaluating the safety and tolerability of ALA in 15 subjects of age $\geq 65$ years (ClinicalTrials.gov, NCT02613572), in anticipation of a randomized clinical trial to test the efficacy of ALA in geographic atrophy in AMD.

\section{Methods}

This study was approved by the Institutional Review Board of the University of Pennsylvania (Protocol 822310), and all subjects gave written informed consent prior to participation. The study was conducted according to the World Medical Association Declaration of Helsinki. Subjects were enrolled consecutively from a retina practice without any preference toward gender. Inclusion and exclusion criteria are listed in Table 1. There were no exclusions for pre-existing medications. The study employed an escalating dose design: all subjects took ALA once daily with a nonstandardized breakfast at doses of $600 \mathrm{mg}$ for 5 days, followed by $800 \mathrm{mg}$ for 5 days, and then 1,200 $\mathrm{mg}$ for 5 days. The study chose $600 \mathrm{mg}$ as the low dose formulation as this amount is the higher end of available over-the-counter doses, 1,200 $\mathrm{mg}$ as the high dose because of its increased therapeutic potential, ${ }^{9,10}$ and $800 \mathrm{mg}$ as an intermediate dose. After each dose was taken by the
Table I Inclusion and exclusion criteria

Inclusion criteria
Age $65-90$
Females must be postmenopausal
Males must use contraception during the study
For the study duration, the subject must remain in the country, remain
within 4 hours of travel time, and have access to medical care if needed
Able to give informed consent
Exclusion criteria
Blood pressure $>190 / 100$ at the time of the baseline visit
Pulse $>100$ at the time of the baseline visit
Acute and ongoing systemic infection
History of dementia
Any unstable medical condition (in the opinion of the investigator)
Geographic atrophy of the macula, and the investigator believes the
subject is a candidate for enrollment into the planned Phase II trial ${ }^{a}$ for
geographic atrophy

Note: ${ }^{2}$ ClinicalTrials.gov, NCT02613572.

subjects for 5 days, each subject was contacted by phone, at which time a complete review of systems was performed and the subject was asked if he or she thought that the dose could be taken daily for 18 months. The subject questionnaire used in the study is presented in Table 2. If there were no safety concerns at a particular dose, then the subject was asked to increase the dose of ALA as planned. Racemic ALA was obtained from Pure Encapsulations (Sudbury, MA, USA),

\section{Table 2 Patient questionnaire}

\begin{tabular}{l} 
I. What dose of medication were you assigned to for the past five \\
days? ( ) $600 \mathrm{mg} /$ day ( ) $800 \mathrm{mg} /$ day ( ) I,200 mg/day \\
2. Have you taken the study medication as directed for the past five \\
days? \\
3. Have you had any acute medical issues requiring you to call your \\
doctor or go to the hospital? \\
4. Have you developed any skin rash? \\
5. Have you developed any fever? \\
6. Have you developed any headache? \\
7. Have you developed any dizziness? \\
8. Have you developed any neurologic issue requiring medical \\
attention? \\
9. Have you developed any chest pain or cardiac issue requiring \\
medical attention? \\
10. Have you developed any vomiting? \\
II. Have you developed any muscle weakness? \\
12. Have you developed any difficulty breathing? \\
13. Have you developed any diarrhea or upset stomach? \\
14. Have you developed any flushing sensation of your skin? \\
15. Have you developed any urine odor? \\
16. Have you developed any other urinary abnormality? \\
17. Have you developed any vision problems such as blurry vision or \\
new floaters? \\
18. If you are a diabetic, have your sugars been unusually high or low? \\
19. Have you had any other medical problems or symptoms that you \\
have not already told me about in the past five days? If yes, specify. \\
20. Are you willing to continue to the next higher medication dosage? \\
\hline
\end{tabular}


and the purity was confirmed by liquid chromatography/mass spectrometry at the University of Pennsylvania. Fisher's exact test was used to compare the rate of adverse events across groups by age, gender, and dose levels. All the statistical analyses were performed in SAS v9.3 (SAS Institute Inc., Cary, NC, USA).

\section{Results}

The average age of the patients was 70.8 years (range 65-77), and there were ten females and five males. There were 12 Caucasians and three African-Americans. Past medical histories in the 15 subjects included history of stroke (one), coronary artery disease necessitating stenting (one), history of pulmonary embolism (one), sarcoidosis (one), diabetes (three), gastric reflux (six), hypertension (eleven), hyperlipidemia (ten), and atrial fibrillation or flutter (four). All subjects also carried a retinal diagnosis, including nonexudative AMD without geographic atrophy (five), exudative AMD (three), retinal vein occlusion (two), diabetic retinopathy (one), retinoschisis (one), myopic degeneration (one), pattern dystrophy (one), and epiretinal membrane (one).

The adverse events reported are shown in Table 3 , and the total number at each dose was $16(600 \mathrm{mg}), 19(800 \mathrm{mg})$, and $19(1,200 \mathrm{mg})$. The number of patients with any adverse event reported at each dose was eleven of 15 (600 $\mathrm{mg})$, ten of $15(800 \mathrm{mg})$, and ten of $14(1,200 \mathrm{mg})$; some adverse events reported by subjects at lower doses were not reported at higher doses. There were no reported changes in vision.

Table 3 Frequency of adverse event per dose

\begin{tabular}{|c|c|c|c|}
\hline Adverse event & $600 \mathrm{mg}$ & $800 \mathrm{mg}$ & $1,200 \mathrm{mg}$ \\
\hline Acid reflux & I & I & 2 \\
\hline Diarrhea & 2 & I & I \\
\hline Dizziness & 0 & 0 & I \\
\hline Dysuria & 0 & 0 & I \\
\hline Fatigue & 1 & I & 0 \\
\hline Flushing sensation of the skin & 0 & I & 1 \\
\hline Hot flashes & 1 & 0 & I \\
\hline Hyperglycemia & 1 & I & 0 \\
\hline Insomnia & I & 0 & I \\
\hline Loose stools & 0 & 3 & I \\
\hline Muscle cramps & 0 & I & 0 \\
\hline Nasal congestion & 0 & I & 0 \\
\hline Nausea & 0 & 0 & I \\
\hline Rash & I & 0 & 0 \\
\hline Stomach discomfort & 0 & 0 & 1 \\
\hline Urinary frequency & 0 & I & 0 \\
\hline Urinary urgency & 0 & 0 & I \\
\hline Urine odor & 8 & 7 & 7 \\
\hline Weakness & 0 & I & 0 \\
\hline Total & 16 & 19 & 19 \\
\hline
\end{tabular}

The most common adverse events reported were urine odor and GI side effects. Eleven of 15 subjects experienced the known side effect of urine odor ${ }^{9}$ at some point during the study. Three of the 15 subjects (one at $600 \mathrm{mg}$, one at $800 \mathrm{mg}$, and three at 1,200 mg) experienced upper GI side effects, including acid reflux, nausea, and stomach discomfort. Another subject also described a generalized "flushing sensation", which could be related to acid reflux at the $800 \mathrm{mg}$ and 1,200 mg doses. Five of the 15 subjects (two at $600 \mathrm{mg}$, three at $800 \mathrm{mg}$, and two at 1,200 mg) experienced lower GI side effects, including loose stools and frank diarrhea (two subjects). With this small sample size, there were no statistically significant differences in the number of adverse events or the number of GI adverse events reported when the subjects were split into groups according to sex or age (Table 4). There was perhaps a trend for higher doses of ALA to be associated with more GI adverse events, but this was not statistically significant (Table 4). One subject was taking thyroid hormone supplementation (levothyroxine), a medication that may potentially be affected by concurrent use of ALA. ${ }^{22}$ This subject experienced urine odor, urinary urgency, and both upper and lower GI side effects.

Given the authors' interest in ALA's potential as a chronic treatment for AMD, all subjects were asked if they could tolerate each dose if taken daily for 18 months. The subject with the flushing sensation stated that she could not tolerate the $800 \mathrm{mg}$ or $1,200 \mathrm{mg}$ dose for 18 months. Two additional subjects stated that they could not tolerate the dose of 1,200 mg for 18 months because of upper GI side effects. These three subjects were not taking any GI prophylaxis medications. There were no upper GI side effects reported by the

Table 4 Comparison of AE rates across different groups

\begin{tabular}{|c|c|c|c|}
\hline & $\begin{array}{l}\text { Number } \\
\text { of subjects }\end{array}$ & $\begin{array}{l}\text { Number of } \\
\text { subjects with } \\
\text { any AE (\%) }\end{array}$ & $\begin{array}{l}\text { Number of } \\
\text { subjects with } \\
\text { any GI AE (\%) }\end{array}$ \\
\hline \multicolumn{4}{|l|}{ Gender } \\
\hline Males & 5 & $5(100)$ & $2(40)$ \\
\hline Females & 10 & $9(90)$ & $6(60)$ \\
\hline$P$-value* & & 1.00 & 0.61 \\
\hline \multicolumn{4}{|l|}{ Age } \\
\hline$\leq 70$ years & 8 & $7(87.5)$ & $3(37.5)$ \\
\hline$>70$ years & 7 & $7(100)$ & $5(7 I .4)$ \\
\hline$P$-value* & & 1.00 & 0.31 \\
\hline \multicolumn{4}{|c|}{ ALA dose level } \\
\hline $600 \mathrm{mg}$ & 15 & II (73.3) & $3(20)$ \\
\hline $800 \mathrm{mg}$ & 15 & $10(66.7)$ & $5(33.3)$ \\
\hline $\mathrm{I}, 200 \mathrm{mg}$ & 14 & $10(71.4)$ & $6(42.9)$ \\
\hline$P$-value* & & 1.00 & 0.44 \\
\hline
\end{tabular}

Note: ${ }^{* P}$-value was calculated using Fisher's exact test.

Abbreviations: AE, adverse event; ALA, alpha lipoic acid; GI, gastrointestinal. 
four subjects who were taking GI prophylaxis medications and the two subjects taking probiotics at baseline and throughout their participation. One subject was withdrawn from the study after 5 days of the $800 \mathrm{mg}$ dose because she wanted to delay the start of the 1,200 $\mathrm{mg}$ dose beyond the planned completion date of the study. No subject had a serious adverse event.

\section{Discussion}

Lipoic acid has potential benefits in multiple systemic and ocular diseases. ${ }^{8-17,21}$ However, human studies of lipoic acid have struggled to find the optimal dosage due to side effects, alterations in rates of metabolism of different formulations of lipoic acid manufactured by different suppliers, and variations in absorption and clearance of lipoic acid across individuals. ${ }^{11}$ The present study evaluated three different doses in the elderly population, and the majority of subjects reported at least one adverse event at each dose, the most common of which was the known side effect of urine odor. ${ }^{9}$ The frequency of adverse events recorded could be high because subjects received planned phone calls during which a complete review of systems was performed. While there were no significant safety concerns among the reported adverse events, there was some GI intolerability that developed at higher doses of ALA. This is in contrast to Yadav et al, ${ }^{10}$ who observed excellent tolerability of 1,200 mg of ALA. This difference could be related to the younger age of patients in their study, or that their participants were given a standardized meal along with the medication, as opposed to this study in which patients were only recommended to take the medication along with their typical breakfast. Another possibility is that taking ALA concurrently with a meal does not completely reduce GI side effects.

\section{Conclusion}

Although 1,200 mg of ALA taken daily with a meal has been shown in other studies to have a potentially therapeutic peak serum concentration, not all subjects in the elderly population can tolerate this dose. This is primarily due to the increased incidence of GI side effects compared to those caused by lower doses. GI prophylaxis medications may reduce the incidence of these side effects. Although this study is not placebo controlled and is limited by its small sample size, these preliminary data should be taken into consideration in future research evaluating the clinical utility of ALA.

\section{Acknowledgment}

The authors have neither received any grant support for this article nor have any proprietary interest in the data presented.

\section{Disclosure}

The authors report no conflicts of interest in this work.

\section{References}

1. Rochette L, Ghibu S, Richard C, Zeller M, Cottin Y, Vergely C. Direct and indirect antioxidant properties of alpha-lipoic acid and therapeutic potential. Mol Nutr Food Res. 2013;57(1):114-125.

2. Salinthone S, Yadav V, Schillace RV, Bourdette DN, Carr DW. Lipoic acid attenuates inflammation via cAMP and protein kinase A signaling. PLoS One. 2010;5(9):e13058.

3. Brantley MA Jr, Osborn MP, Sanders BJ, et al. The short-term effects of antioxidant and zinc supplements on oxidative stress biomarker levels in plasma: a pilot investigation. Am J Ophthalmol. 2012;153(6): 1104-1109.e1102.

4. Moriarty-Craige SE, Adkison J, Lynn M, et al. Antioxidant supplements prevent oxidation of cysteine/cystine redox in patients with age-related macular degeneration. Am J Ophthalmol. 2005;140(6): 1020-1026.

5. Shay KP, Moreau RF, Smith EJ, Smith AR, Hagen TM. Alpha-lipoic acid as a dietary supplement: molecular mechanisms and therapeutic potential. Biochim Biophys Acta. 2009;1790(10):1149-1160.

6. Age-Related Eye Disease Study Research Group. A randomized, placebo-controlled, clinical trial of high-dose supplementation with vitamins $\mathrm{C}$ and $\mathrm{E}$, beta carotene, and zinc for age-related macular degeneration and vision loss: AREDS report no 8. Arch Ophthalmol. 2001; 119(10):1417-1436.

7. Age-Related Eye Disease Study 2 Research Group. Lutein + zeaxanthin and omega-3 fatty acids for age-related macular degeneration: the Age-Related Eye Disease Study 2 (AREDS2) randomized clinical trial. JAMA. 2013;309(19):2005-2015.

8. Ziegler D, Ametov A, Barinov A, et al. Oral treatment with alpha-lipoic acid improves symptomatic diabetic polyneuropathy: the SYDNEY 2 trial. Diabetes Care. 2006;29(11):2365-2370.

9. Yadav V, Marracci G, Lovera J, et al. Lipoic acid in multiple sclerosis: a pilot study. Mult Scler. 2005;11(2):159-165.

10. Yadav V, Marracci GH, Munar MY, et al. Pharmacokinetic study of lipoic acid in multiple sclerosis: comparing mice and human pharmacokinetic parameters. Mult Scler. 2010;16(4):387-397.

11. Plemel JR, Juzwik CA, Benson CA, Monks M, Harris C, Ploughman M. Over-the-counter anti-oxidant therapies for use in multiple sclerosis: a systematic review. Mult Scler. 2015;21(12):1485-1495.

12. Shinto L, Quinn J, Montine T, et al. A randomized placebo-controlled pilot trial of omega-3 fatty acids and alpha lipoic acid in Alzheimer's disease. J Alzheimers Dis. 2014;38(1):111-120.

13. Kowluru RA, Odenbach S. Effect of long-term administration of alpha-lipoic acid on retinal capillary cell death and the development of retinopathy in diabetic rats. Diabetes. 2004;53(12):3233-3238.

14. Berkowitz BA, Roberts R, Stemmler A, Luan H, Gradianu M. Impaired apparent ion demand in experimental diabetic retinopathy: correction by lipoic acid. Invest Ophthalmol Vis Sci. 2007;48(10):4753-4758.

15. Inman DM, Lambert WS, Calkins DJ, Horner PJ. $\alpha$-Lipoic acid antioxidant treatment limits glaucoma-related retinal ganglion cell death and dysfunction. PLoS One. 2013;8(6):e65389.

16. Andrade AS, Salomon TB, Behling CS, et al. Alpha-lipoic acid restores tear production in an animal model of dry eye. Exp Eye Res. 2014;120:1-9.

17. Chaudhary P, Marracci G, Yu X, Galipeau D, Morris B, Bourdette D. Lipoic acid decreases inflammation and confers neuroprotection in experimental autoimmune optic neuritis. J Neuroimmunol. 2011; 233(1-2):90-96.

18. Holz FG, Strauss EC, Schmitz-Valckenberg S, van Lookeren Campagne M. Geographic atrophy: clinical features and potential therapeutic approaches. Ophthalmology. 2014;121(5):1079-1091.

19. Dunaief JL. Iron induced oxidative damage as a potential factor in agerelated macular degeneration: the cogan lecture. Invest Ophthalmol Vis Sci. 2006;47(11):4660-4664. 
20. Lindblad AS, Lloyd PC, Clemons TE, et al; Age-Related Eye Disease Study Research Group. Change in area of geographic atrophy in the Age-Related Eye Disease Study: AREDS report number 26. Arch Ophthalmol. 2009;127(9):1168-1174.

21. Zhao L, Wang C, Song D, et al. Systemic administration of the antioxidant/ iron chelator $\alpha$-lipoic acid protects against light-induced photoreceptor degeneration in the mouse retina. Invest Ophthalmol Vis Sci. 2014;55(9): 5979-5988.
22. Segermann J, Hotze A, Ulrich H, Gao GS. Effect of alpha-lipoic acid on the peripheral conversion of thyroxine to triiodothyronine and on serum lipid, protein, and glucose levels. Arzneimittelforschung. 1991;41(12): 1294-1298.

\section{Publish your work in this journal}

Clinical Ophthalmology is an international, peer-reviewed journal covering all subspecialties within ophthalmology. Key topics include: Optometry; Visual science; Pharmacology and drug therapy in eye diseases; Basic Sciences; Primary and Secondary eye care; Patien Safety and Quality of Care Improvements. This journal is indexed on

Submit your manuscript here: http://www.dovepress.com/clinical-ophthalmology-journal

\section{Dovepress}

PubMed Central and CAS, and is the official journal of The Society of Clinical Ophthalmology (SCO). The manuscript management system is completely online and includes a very quick and fair peer-review system, which is all easy to use. Visit http://www.dovepress.com/ testimonials.php to read real quotes from published authors. 